\title{
Longitudinally extensive transverse myelitis with mycobacterium tuberculosis infection
}

\author{
Le Fang ${ }^{1} \cdot$ Yushuang Gong ${ }^{1} \cdot \mathrm{Kai} \mathrm{Han}^{1} \cdot$ Yalin $\mathrm{Lv}^{1} \cdot \mathrm{Miao} \mathrm{Li}^{2} \cdot \mathrm{Jie} \mathrm{Wang}^{1}(\mathbb{C}$
}

Received: 14 March 2021 / Accepted: 10 June 2021 / Published online: 5 July 2021

(c) The Author(s) 2021

\section{Dear Editor,}

Longitudinal extensive transverse myelitis (LETM) is defined as a spinal cord lesion that extends over three or more vertebrae, as seen on MRI of the spine [1]. LETM is a common characteristic feature of neuromyelitis optica spectrum disease (NMOSD) or various autoimmune diseases [2]. While in some cases, the common antibodies are negative and related to some hidden and unknown causes. We report a vegetarian woman presented sudden onset of quadriplegia with LETM in cervical and thoracic spinal cord which was confirmed with neuroimaging. On MRI, the patient was found exhibit atypical longitudinal extensive transverse abnormal signals that mimicked NMOSD. We tracked for possible reasons that may be related to LETM and found encranial and pulmonary Mycobacterium tuberculosis (MTB) infection. Systemic screening indicated there was no evidence supporting autoimmune diseases such as NMOSD or paraneoplastic neurological syndrome (PNS). The patient showed good clinical response to anti-tuberculosis therapy, corticosteroids and immunoglobin.

Usually diagnosis of LETM from NMOSD or tracking for autoimmune reasons of LETM is difficult. Our case highlights that MTB infection might be an important but overlooked cause of LETM. Symptoms of MTB are usually nonspecific, as seen in the current case, and the duration of symptoms before diagnosis can vary [3].

Jie Wang

wang_jie@jlu.edu.cn

1 Department of Neurology, The China-Japan Union Hospital of Jilin University, Changchun 130031, China

2 Department of Neurosurgery, The China-Japan Union Hospital of Jilin University, Changchun 130031, China

\section{Case report}

A 45-year-old woman of Han Nationality was admitted to our hospital in April 2018. She developed rapidly progressive paraparesis, sensory disturbances, bladder/bowel dysfunction and dyspnea. The first onset symptom was numbness in both lower limbs then quickly developed to paraparesis and dyspnea. The patient was hospitalized to neurointensive care unit to receive close observation and treatment. The patient showed paraparesis, sensory disturbances, bladder/bowel dysfunction and dyspnea, as while as hysphagia, Horner's syndrome and low-grade fever. The patient had palpitations, chest tightness, constipation, like Horner's syndrome, were certain extent related to dysautonomia. She denied the apparent pain in the back or chest. She denied any history of infection, tumor or contact of special medcines.

Physical examination: The patient had normal consciousness, normal blood pressure, increasing heart rate $(100-110 / \mathrm{min})$ and harsh respiration. The body temperature was $37.0-38.0^{\circ} \mathrm{C}$. She complained mild dyspnea and some chest tightness. There was Horner's syndrome in the left side. The bilateral lower limbs power was $0 / 5$ and bilateral upper limbs power was $3 / 5$ with absent reflexes in all limbs. The abdominal reflexes were absent. The sensory level was identified at T2 and the deep and shallow senses below T2 level obviously declined. The pyramidal signs of Babinski's were positive in both sides. There was no skin rash and no lymphadenectasis. The patient got acute urinary retention soon after hospitalization and received indwelling catheter.

Laboratory findings: peripheral blood examinations: RBC $4.21 \times 10^{12} / \mathrm{L}, \mathrm{WBC} 8.38 \times 10^{9} / \mathrm{L}$, neutrophilic granulocyte $82.4 \%$, lymphocyte $12.2 \%$, hemoglobin (HG) $132.0 \mathrm{~g} / \mathrm{L}$. Blood glucose $5.86 \mathrm{mmol} / \mathrm{L}$, renal and liver functions were normal. Erythrocyte sedimentation rate (ESR) was $20 \mathrm{~mm} / \mathrm{h}$. Serum markers for autoimmune and connective tissues (ANA, Anti-dsDNA, Anti-nucleosome, Antihistones, Anti-Sm, Anti SS-A, Anti RO, Anti Scl-70, Anti 
Rib-P-Protein, Anti-JO, Anti-SS-B) were negative. Immunoglobulin IgG, IgA, IgM, C3, C4 were normal. Blood culture was negative. Serology results for tubercle bacillus, rubella and Epstein-Barr virus, Lyme and brucella were negative. Serum viral serology for hepatitis B virus (HBV), hepatitis $\mathrm{C}$ virus (HCV) and human immunodeficiency virus were unremarkable. Antiphospholipids antibody (APLA) was negative. Skin tuberculin sensitivity test was positive. Polymerase chain reaction (PCR) for MTB on three consequtive sputum samples was positive.

The lumbar puncture revealed intracranial pressure (ICP) was $20 \mathrm{cmH}_{2} \mathrm{O}\left(1 \mathrm{cmH}_{2} \mathrm{O}=9.8 \mathrm{kPa}\right)$. Cerebrospinal fluid (CSF) examinations: CSF protein $28 \mathrm{mg} / \mathrm{dL}, \mathrm{WBC} 0$, glucose $86.4 \mathrm{mg} / \mathrm{dL}$, chloridum $431.4 \mathrm{mg} / \mathrm{dL}, \mathrm{NMO} / \mathrm{AQP} 4$ antibodies, MOG antibodies, myelin basal protein (MBP) and oligoclonal bands (OB) detection were absent in serum and CSF. CSF culture for bacterium was negative. PCR for MTB in CSF was positive while PCR for herpes simplex virus was negative. CSF acid-fast bacillus (AFB) stain, and an agglutination test for brucella were negative.

Images: magnetic resonance imaging (MRI) showed hyperintens best appreciated on T-2-weighted sections, showing long segment myelitis, extending from C5-T2 (Fig. 1). The pulmonary CT scan suggested active pulmonary tuberculosis in bilateral upper lobes.
The clinical and imaging findings supported a diagnosis of LETM and pulmonary tuberculosis. The differential diagnosis required spinal cord ischemia as its acute onset. As the patient had no obvious neuroroot pain and the longitudinal extensive lesions of cervical and thoracic vetebrae did not meet the anatomical vascular supply, which was not consistent with the characteristics of ischemia. Furthermore, the patient was a 45-year-old woman with no risk factors for vascular disease, such as hypertension or diabetes. LETM and pulmonary tuberculosis were finally diagnosed. The patient received high-dose and short-period steroid therapy (500 mg of methylprednisolone intravenously per day for five continuous days, then halve the dose and stop it after 2 days) and intravenous immunoglobin ( $400 \mathrm{mg} / \mathrm{kg}$ per day for five continuous days). At the same time, the patient received sufficient anti-tuberculosis therapy. The patient showed satisfied recovery and was afebrile without chest tightness or dysphagia. Muscle strength of the extremities gradually recovered. On 1 month follow-up, the bilateral lower limbs power was $3 / 5$ and bilateral upper limbs power was $4 / 5$. The patient was able to stand with part of support. She still complained of occasional urinary incontinence. MRI obtained 1 month after the onset of the disease showed the lesions were significantly absorbed compared with the anterior imaging (Fig. 2).
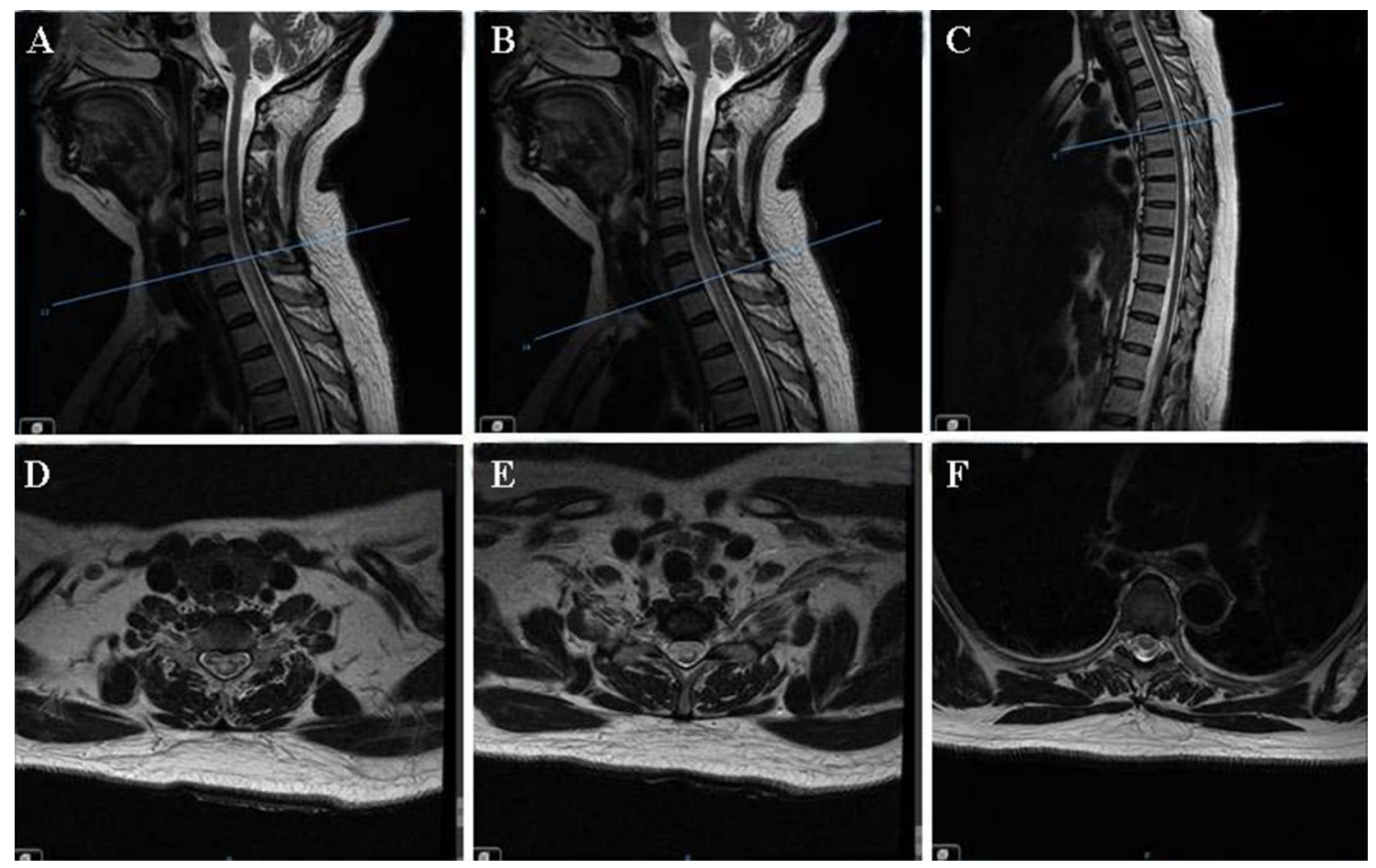

Fig. 1 Magnetic resonance imaging (MRI) obtained on the third day of onset of the disease (sagittal section $\mathbf{A}-\mathbf{C}$; transverse section corresponding to the scaleplate respectively $\mathbf{D}-\mathbf{F})$. T2 hyperintense lin- ear mass best appreciated on sagittal sections, showing long segment myelitis, extending from $\mathrm{C} 5-\mathrm{T} 2$ 

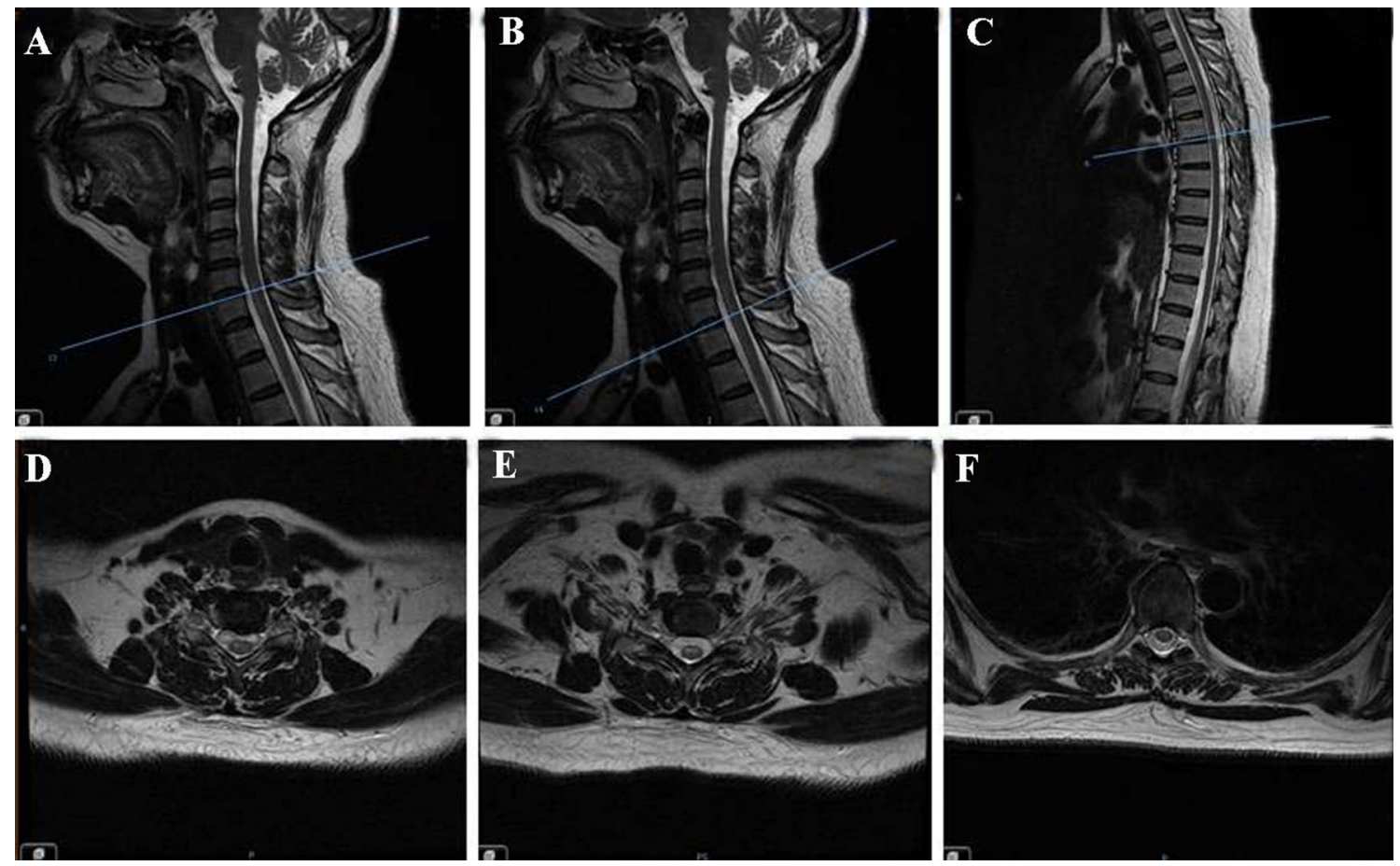

Fig. 2 Magnetic resonance imaging (MRI) obtained one month of onset of the disease (sagittal section A-C; transverse section corresponding to the scaleplate, respectively $\mathbf{D}-\mathbf{F})$. The lesions were significantly absorbed compared with the anterior imaging

\section{Discussion}

LETM often indicates initiating systemic immune responses for known or unknown reasons, which is different from short extensive myelitis. Typically LETM is associated with NMOSD with positive serum NMO/AQP4 antibodies [2]. However, not all LETM are NMOSD [4, 5]. Hyun JW followed up 108 patients with LETM for at least 2 years and found nearly half of cases were idiopathic aquaporin-4 antibody negative LETM with different features, which could not be simply diagnosed as NMOSD. When aquaporin-4 antibody is negative, it is necessary to be very careful in diagnosis of NMOSD [2, 5]. LETM can occur in various autoimmune diseases, such as multiple sclerosis (MS), systemic lupus erythematosus (SLE) or Sjögren syndrome, or follow infectious diseases, such as tuberculosis infection and HIV infection [6-8]. There is view that MTB may share antigens with myelin basic protein although no antibodies are found so far [8]. The possible infectious agents such as MTB are worth further discussing or exploring. Recently report reveal transverse myelitis can also occur following SARSCoV-2 infection [9]. The pathogenesis of LETM is unclear so far and few correlative factors are reported or studied.

We report a patient developed LETM in cervical and thoracic spinal cord with possible antigenicity related to MTB. Diagnosis of LETM was made according to the clinical manifestation and radiological data. We tracked for possible reasons that may be related to LETM, while there was no evidence supporting autoimmune diseases such as NMOSD, PNS or other infection except MTB. Laboratory findings indicated conceivable intracranial MTB infection and active pulmonary tuberculosis. Although initial investigations were equivocal for an infectious etiology, subsequent investigations led to a diagnosis of LETM with MTB infection. PCR for MTB in the CSF is a very specific test with high sensitivity, which suggests acute or previous intracranial MTB infection [10]. Tubercular etiology and its associated immune response were suggested in our case in view of positive TB-PCR in the CSF and pulmonary tuberculosis.

Association between LETM and MTB is a very worthy of discussion. The pathogenesis of LETM remained unclear science the absence of pathological data and failed to find any specific antibody. Associations between NMOSD and pulmonary tuberculosis have been suggested by a number of case reports and series, the most likely mechanism being immune-mediated inflammatory demyelination of the optic nerves and spinal cord triggered by infection of MTB [8, $11,12]$. Li R investigated neuromyelitis optica and tuberculosis in a Chinese population and put forward the view that MTB may shares antigens with myelin basic protein (MBP) [8]. Sahu reported four cases of LETM with mycobacterium tuberculosis and highlight the fact that MTB infection might be more common than usually suspected in LETM [13]. 
Usually LETM is difficulty to make etiological diagnosis and needs to be distinguished from NMOSD or abscesses [14].

Based on our belief that the immune injury was the main pathological process, short-period corticosteroids and immunoglobin were administrated. The patient showed good clinical response to anti-tuberculosis therapy, corticosteroids and immunoglobin. Corticosteroids are not absolute controversial in the treatment of central nervous system tuberculosis [15]. We believe that short-period corticosteroids may be adjuvant to antituberculous treatment. Although pathological data were not available in this case, we hypothesized that MTB shares antigens with myelin basic protein, thus sensitizing lymphocytes to mycobacterium and facilitating their attachment to myelin. LETM may develop by possible antigenicity from MTB. The antigenicity need to rely on further experimental confirmation, especially base on establishment of reliable animal models.

Our case highlights the fact that MTB might be an important but overlooked cause of LETM. LETM should be diagnosed considerately from NMOSD and searching for relevant factors is needed. Prompt identification of underlying etiology by contrast examination and systemic survey is cruci al for the patient assumed as LETM.

Funding The National Natural Science Fund (Grant no. 81771304), the National Natural Science Youth Fund (Grant no. 81601073), the "13.5" Science and Technology Research Planning Project of Jilin Education Department (No. JJKH20190079KJ).

\section{Declarations}

Conflict of interest The authors declare that they do not have any conflict of interest.

Ethical approval The study design was approved by the ethics committee of China-Japan Union Hospital of Jilin University.

Informed consent Obtained.

Open Access This article is licensed under a Creative Commons Attribution 4.0 International License, which permits use, sharing, adaptation, distribution and reproduction in any medium or format, as long as you give appropriate credit to the original author(s) and the source, provide a link to the Creative Commons licence, and indicate if changes were made. The images or other third party material in this article are included in the article's Creative Commons licence, unless indicated otherwise in a credit line to the material. If material is not included in the article's Creative Commons licence and your intended use is not permitted by statutory regulation or exceeds the permitted use, you will need to obtain permission directly from the copyright holder. To view a copy of this licence, visit http://creativecommons.org/licenses/by/4.0/.

\section{References}

1. Trebst C, Raab P, Voss EV, Rommer P, Abu-Mugheisib M, Zettl UK, Stangel M (2011) Longitudinal extensive transverse myelitisit's not all neuromyelitis optica. Nat Rev Neurol 7(12):688-698

2. Wingerchuk DM, Banwell B, Bennett JL, Cabre P, Carroll W et al (2015) International consensus diagnostic criteria for neuromyelitis optica spectrum disorders. Neurology 85(2):177-189

3. Wang JY, Hsueh PR, Wang SK, Jan IS, Lee LN, Liaw YS et al (2007) Disseminated tuberculosis: a 10-year experience in a medical center. Medicine (Baltimore) 86:39-46

4. Trebst C, Raab P, Voss EV, Rommer P, Abu-Mugheisib M et al (2011) Longitudinal extensive transverse myelitis-it's not all neuromyelitis optica. Nat Rev Neurol 7(12):688-698

5. Hyun JW, Kim SH, Huh SY, Kim W, Yun J, Joung A, Sato DK, Fujihara K, Kim HJ (2015) Idiopathic aquaporin-4 antibody negative longitudinally extensive transverse myelitis. Mult Scler 21(6):710-717

6. Tohge R, Shinoto Y, Takahashi M (2017) Longitudinally extensive transverse myelitis and optic neuropathy associated with syphilitic meningomyelitis and human immunodeficiency virus infection: a case report and review of the literature. Intern Med 56(15):2067-2072

7. Feng YQ, Guo N, Huang F, Chen X, Sun QS et al (2010) Antituberculosis treatment for Devic's neuromyelitis optica. J Clin Neurosci 17:1372-1377

8. Li R, Zhong X, Qiu W, Wu A, Dai Y, Lu Z et al (2014) Association between neuromyelitis optica and tuberculosis in a Chinese population. BMC Neurol 14:33

9. (2021) Acute transverse myelitis with dysautonomia following SARS-CoV-2 infection: a case report and review of literature. J Neuroimmunol 353:577523

10. Liu PY, Shi ZY, Lau YJ, Hu BS (1994) Rapid diagnosis of tuberculous meningitis by a simplified nested amplification protocol. Neurology 44:1161-1164

11. Zatjirua V, Butler J, Carr J, Henning F (2011) Neuromyelitis optica and pulmonary tuberculosis: a case-control study. Int $\mathrm{J}$ Tuberc Lung Dis 15:1675-1680

12. Sridhar S, Chan JF, Yuen KY (2014) Fatal anti-aquaporin-4 seropositive neuromyelitis optica spectrum disorder in tuberculosis. BMC Infect Dis 28(14):470

13. Sahu SK, Giri S, Gupta N (2014) Longitudinal extensive transverse myelitis due to tuberculosis: a report of four cases. J Postgrad Med 60(4):409-412

14. Kasundra GM, Sood I, Bhushan B, Bhargava AN, Shubhkaran K (2016) Distal cord-predominant longitudinally extensive myelitis with diffuse spinal meningitis and dural abscesses due to occult tuberculosis: a rare occurrence. J Pediatr Neurosci 11:77-79

15. Prasad K, Singh MB, Ryan H (2016) Corticosteroids for managing tuberculous meningitis. Cochrane Database Syst Rev 4:2244

Publisher's Note Springer Nature remains neutral with regard to jurisdictional claims in published maps and institutional affiliations. 